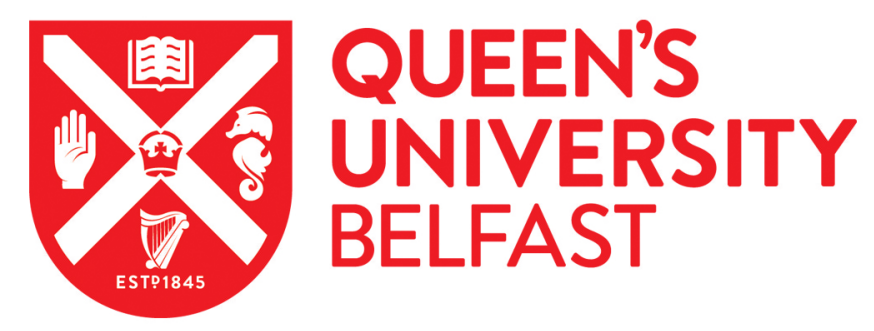

\title{
Invariant based approaches in the design of composite laminates
}

Millen, S. L. J., Falzon, B., \& Aravand, M. A. (2021). Invariant based approaches in the design of composite laminates. Composites Science and Technology, 202, [108526].

https://doi.org/10.1016/j.compscitech.2020.108526

\section{Published in:}

Composites Science and Technology

\section{Document Version:}

Peer reviewed version

\section{Queen's University Belfast - Research Portal:}

Link to publication record in Queen's University Belfast Research Portal

\section{Publisher rights}

Copyright 2020 Elsevier

This manuscript is distributed under a Creative Commons Attribution-NonCommercial-NoDerivs License

(https://creativecommons.org/licenses/by-nc-nd/4.0/), which permits distribution and reproduction for non-commercial purposes, provided the author and source are cited.

\section{General rights}

Copyright for the publications made accessible via the Queen's University Belfast Research Portal is retained by the author(s) and / or other copyright owners and it is a condition of accessing these publications that users recognise and abide by the legal requirements associated with these rights.

Take down policy

The Research Portal is Queen's institutional repository that provides access to Queen's research output. Every effort has been made to ensure that content in the Research Portal does not infringe any person's rights, or applicable UK laws. If you discover content in the Research Portal that you believe breaches copyright or violates any law, please contact openaccess@qub.ac.uk. 


\title{
ACCEPTED MANUSCRIPT
}

\section{Invariant Based Approaches in the Design of Composite Laminates}

\author{
S.L.J. Millen ${ }^{a, b}$, B. G. Falzon ${ }^{a, b}$, M. A. Aravand ${ }^{a, b+}$
}

${ }^{a}$ Advanced Composites Research Group (ACRG), School of Mechanical and Aerospace Engineering, Queen's University Belfast, Ashby Building, Belfast. Northern Ireland, BT9 5AH, U.K.

${ }^{b}$ Northern Ireland Advanced Composites and Engineering (NIACE) centre, Airport Road, Belfast. Northern Ireland, BT3 9DZ, UK

+ Corresponding author:Tel.: +44(0) 289097 4113; E-mail:m.aravand@qub.ac.uk

\begin{abstract}
Invariant based approaches have been proposed to simplify the design and analysis of composite materials, in particular, for generating design allowables. Of these invariants, Trace, more recently referred to as Tsai's Modulus, a material property derived from the plane stress stiffness matrix, can be used to help with preliminary design. However, in literature this has mainly focussed on unidirectional composites. The present work extends the application of invariants to woven and hybrid composites, i.e. the latter made with both unidirectional and woven laminae, and provides appropriate validation for the use of invariants in design. A novel approach to implement Tsai's Modulus and determine the three-dimensional stiffness matrix of a woven specimen is proposed. Omni failure envelopes have been proposed in literature and these have been extended to accommodate hybrid specimens with both unidirectional and woven laminae. This work shows that Tsai's Modulus and invariants can be used as an initial design tool in order to establish the likely properties of a given layup and material combination for use in preliminary design. Property predictions at the laminate level, $E_{x}, E_{y}, v_{x y}$ and $G_{x y}$, were within $\pm 10 \%$ of experimental values for highly complex laminate stacking sequences and material combinations.
\end{abstract}

\section{Keywords}

A Laminate; B Mechanical properties; C Elastic properties; C Failure criterion; Tsai’s Modulus 


\subsection{Introduction}

Experimental testing has been the primary method to determine the properties of a given carbon-fibre reinforced polymer (CFRP) composite lamina or laminate. However, recently, new analytical methods have been developed to reduce the extent of experimental testing required. Invariants based on the reduced plane stress stiffness matrix have been proposed by Tsai et al. [1]-[4] using the trace of the [Q] matrix in 2D,

$$
\operatorname{Tr}(\boldsymbol{Q})=Q_{11}+Q_{22}+2 Q_{66}
$$

Recently this concept, $\operatorname{Tr}(\boldsymbol{Q})$, has been referred to as Tsai's Modulus [5], and this name will be used from this point forward in this manuscript. A similar approach can be used for a full 3-dimensional reduced stiffness matrix $[\mathrm{C}]$, where,

$$
\operatorname{Tr}(\boldsymbol{C})=C_{11}+C_{22}++C_{33}+2 C_{44}+2 C_{55}+2 C_{66}
$$

These techniques are used to exploit the invariant nature of the Tsai's Modulus normalised elastic properties of composite plies which are used to predict the stiffness components of laminates for a given layup. The concept of invariance is very useful in the design of laminates since, as the name implies, invariants are not affected by ply orientation. The advantage of Tsai's Modulus is the ability to drastically reduce the number of experimental tests required to give acceptable information for preliminary design or screening on the basis of elastic properties, especially where a building block approach in structural design is used. For example, it is possible to predict the lamina or laminate elastic properties by providing only $E_{1}$ and $v_{12}$ of a lamina i.e. conducting only one experiment. Once the lamina level properties are obtained via Tsai's Modulus and combined with classical lamination theory (CLT) it is possible to estimate the normalised in-plane, coupling and flexural laminate stiffness matrices [6] as well as laminate engineering constants. In addition, a further merit of Tsai's Modulus is that the processing artefacts and features would be taken into account. For example, since the value of Tsai's Modulus is calculated based on an experimental measurement, as long as the specimen is representative of the processing conditions, any related artefact or feature would be taken into account.

The omni and strain space unit circle failure envelopes, methods designed to be complementary to Tsai's Modulus, aim to simplify the failure envelope of laminates thereby leading to streamlined, albeit approximate, 
design tools. This most conservative omni envelope, established in principal strain space, has been shown to be invariant [1], [3]. Here, as with the elastic properties, only limited tests are required to produce the omni envelope, significantly facilitating preliminary design of composite laminates.

This work presents an extension to the established invariant techniques applied beyond unidirectional plies and laminates. Invariance is applied to both woven and hybrid specimens, i.e. the latter made with both unidirectional and woven laminae, with appropriate validation against both published and experimental results.

\subsection{Background}

Typically composite design has involved the study and optimisation of laminate properties such as stiffness [7] or aeroelastic constraints [8], [9] or the reduction of weight to improve fuel efficiency and lower emissions [10]. Laminate thickness, stacking sequence, lamina material [11] and fibre orientation are the main variables in these types of studies [12].

Recently, Tsai and Melo [1] proposed the Master Ply method after observing that, across a broad selection of CFRP composites, normalised stiffness components had only small coefficients of variation. For example in the fibre direction, $Q_{x x}^{*}=Q_{x x} / \operatorname{Tr}(Q)$, where $Q_{x x}^{*}$ is the normalised longitudinal stiffness component, variation was only $1.5 \%$, half of the normal experimental accuracy of $3 \%$ for stiffness data [2]. These master ply values could easily be used to link orthotropic in-plane engineering constants with $\operatorname{Tr}(\mathrm{Q})$, Tsai's Modulus [6]. Master laminate factors were also determined using prescribed stacking sequences, CLT and the master ply values [2], [6]. Arteiro et al. [6] noted the potential reduction in experimental tests, from three tests at the ply level, to one test at the ply or laminate level to obtain $\mathrm{E}_{\mathrm{x}}$ and hence the subsequent Tsai's Modulus.

Authors have sought to extend the application of the invariant-based approach beyond simple unidirectional laminae or defined laminates [6], [13], [14]. Arteiro et al. [6] explained the invariant-based approach using micro-mechanics with both rule of mixtures and the Halpin-Tsai models while Gerbaud et al. [14] included viscoelastic behaviour. Ha and Cimini Jr. [13] plotted normalized parameters against the unidirectional ply longitudinal modulus for four material systems (HM carbon/epoxy, SM carbon/epoxy, aramid/epoxy, and glass/epoxy). It was shown that the master ply concept could be applied to all material systems except 
glass/epoxy. The invariant-based approach has been validated at the lamina level by a small number of authors [6], [13], however, thorough validation at the laminate level has been lacking.

A number of methods have been proposed to determine lamina properties for woven fabric composites [15]-[18], focussing either on repeating units or representative volume elements. One of the more simple approaches for woven specimens was that proposed by Akkerman [18]. This approach did not require any tow undulation dimensions or angles but rather only required the mechanical properties of the lamina. This method used a series of equations to generate a compliance matrix for a woven lamina, using equivalent UD properties, based on a cross-ply approximation of equivalent UD plies using CLT. However, a set of ratios or conversion factors to relate equivalent UD properties to woven properties remained unclear. It is currently unclear if invariance could aid the use of this convenient woven fabric design tool.

The omni and strain space unit circle failure envelopes methods, established in principal strain space, designed to be complementary to Tsai's Modulus, aim to simplify the failure envelope of laminates thereby leading to streamlined experimental testing and design tools. The most conservative omni envelope, can be determined by finding the controlling ply that would fail first, i.e. the inner envelope for a laminate for unit loading strain vectors from 0 to $2 \pi[1]$. The advantage of this envelope is that it is invariant since it is independent of layup. Given the nature of the omni failure envelope method, overlaying or superimposing the failure envelopes for each constituent ply, it is possible to simplify a very complex laminate stacking sequences (LSS) to only a few failure envelopes. The disadvantage of this envelope is that it requires four independent elastic constants and five strengths to characterise a ply [1].

Tsai et al. [3] proposed the unit circle failure envelope, a strain normalized failure envelope for any carbon fibre reinforced polymer laminate, which required only determination of the longitudinal tensile and compressive strains-to-failure of a UD ply laminate rather than four elastic constants and five strengths. This envelope was compared with experimental data from the World Wide Failure Exercise [19], [20] and good agreement was found. However, this was only conducted for unidirectional CFRP laminates containing a single ply material system and further research was required for hybrid laminates or woven materials. 


\subsection{Motivation}

In summary there have been considerable developments in the knowledge and application of invariants and Tsai's Modulus in composite design. However, to-date these have been limited almost exclusively to unidirectional CFRP lamina. The combination of invariance and omni and unit circle failure envelopes, requiring limited test data, present an opportunity for simple and quick design toolsets. These toolsets could provide the user with properties sufficient for initial screening of materials and analytical or numerical analysis work. The application of this method and tools developed by Tsai et al. [1]-[4] have not been applied to more complex laminates or woven material systems. Therefore, this work for the first time, assesses the accuracy of Tsai's Modulus and invariants as a design tool for unidirectional and woven specimens, before determining if these errors are translated to the laminate level for unidirectional, woven and hybrid laminates. In addition, the strain space unit circle failure envelope will be applied to unidirectional, woven and hybrid laminates and compared with experimental data if available.

\subsection{Implementation and Validation}

The work presented in this paper addresses three stages of development. The first of these was assessing the application and suitability of Tsai's Modulus invariance as a design tool. This involved using Tsai's Modulus to predict the engineering constants of the given material and establishing the potential inaccuracy of this method at both lamina and laminate levels. To do this experimental data was sourced from NIAR NCAMP [21] repositories as well as Collins Aerospace and Bombardier Belfast. This step also included the extension of Tsai's Modulus and invariance to woven specimens using the method proposed by Akkerman [18] which will be discussed in more detail in a later section.

The second stage of this work was to assess the omni and unit circle failure envelopes and extend these to woven and hybrid laminates. Failure envelopes were generated for a series of materials and stacking sequences and results compared with physical test data.

\subsection{Assessing Tsai's Modulus}


The first step of this work assessed the applicability of invariance to different composite laminae and laminates. This was done in several stages. The first of these compared predictions directly with unidirectional specimens, as in previous literature [1], [13], in order to check the implementation of the method, before extending this to 3D stiffness matrices to calculate out-of-plane elastic constants based on normalised values. In this step a direct comparison of Tsai's Modulus for both tensile and compressive moduli was made, where possible, to determine their variance. In addition, the predictions of in-plane and out-of-plane shear properties were compared with experimental data.

\subsubsection{UD Specimens}

UD specimens were considered using the master ply, normalised elasticity values proposed previously by Tsai and Melo [1]. These master ply values of $0.88,0.052$ and 0.031 for $E_{1}, E_{2}$ and $G_{12}$, respectively, were used. In order to check the applicability of Tsai's Modulus as a design tool it was necessary to establish the accuracy of this method at both lamina and laminate levels. At the lamina level, $\mathrm{E}_{1}$ was supplied to the model before

calculating Tsai's Modulus, $\operatorname{Tr}=E_{1} / 0.88 . E_{2}$ and $G_{12}$ could then be calculated, $E_{2}=\operatorname{Tr} \times 0.052, G_{12}=\operatorname{Tr} \times$ 0.031. Once the full set of lamina input data had been generated, using Tsai's Modulus, the standard approaches could be used for both 2D and 3D stiffness [Q], [C] and compliance [S] matrices.

\subsubsection{Woven Specimens}

The same process as for UD specimens was repeated for woven material systems using a combination of the method used by Akkerman [18], i.e., a 3D woven stiffness matrix generated from equivalent UD properties, and Tsai's Modulus. To date, Tsai's Modulus has been used on UD laminae with differing E1 and E2 values, however, balanced woven composites typically have similar or identical $E_{1}$ and $E_{2}$ values. 2D stiffness matrices for woven specimens can be calculated in the same manner as UD specimens, however, this becomes more complex for 3D stiffness matrices. Therefore, a different approach is required. In this work, the method used by Akkerman [18], mentioned previously, was used to generate the 3D compliance matrix for the woven lamina, based on equivalent UD properties, as shown in Equation 3 [18]. Here $E_{1}$ and $E_{2}$ are the moduli, $v_{12}$ and $v_{23}$ are the Poisson's ratios 
and $\mathrm{G}_{12}$ is the shear modulus of the equivalent UD lamina. The stiffness matrix for a single lamina was then calculated by the inversion of the compliance matrix.

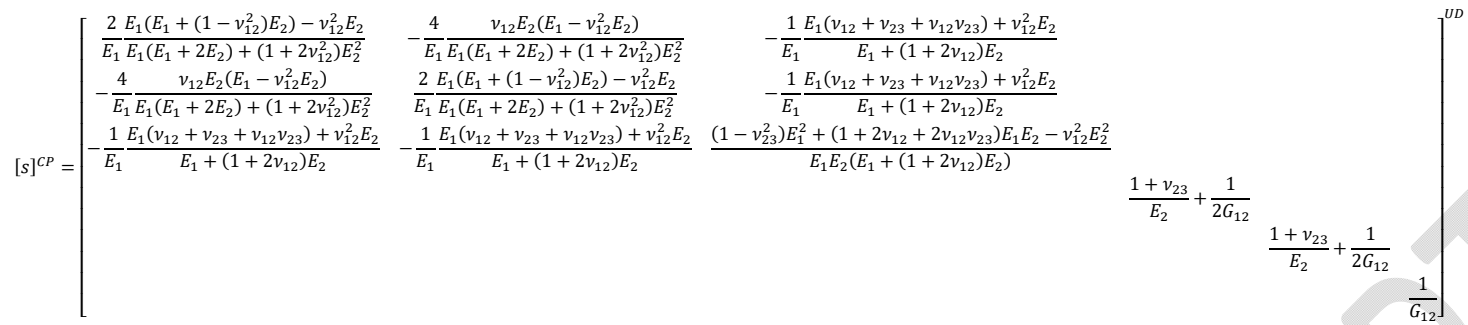

While an example was given of the equivalent UD properties to specify a particular woven lamina, no relationship between the two was proposed. This work has found a convenient relationship between the two using Tsai's Modulus invariants and will be discussed further in Section 4.1.2 Woven Specimens.

The input to the system was $E_{1}$ and $v_{12}$ of the woven lamina. Tsai's Modulus of the woven lamina $\operatorname{Tr}(\boldsymbol{W F})$ was then calculated using the woven invariant property of 0.47 [22], equivalent to a [0/90] laminate, i.e. $\operatorname{Tr}(\boldsymbol{W F})=E_{1}{ }^{W F} / 0.47$. This value is the same for both woven and equivalent UD versions of the material. Therefore the equivalent UD properties could be back calculated from Tsai's Modulus i.e. $\mathrm{E}_{1}{ }^{\mathrm{Eqv} . \mathrm{UD}}=\operatorname{Tr}(\boldsymbol{W F}) * 0.88, \mathrm{E}_{2} \mathrm{Eqv}^{\mathrm{UD}}=$ $\operatorname{Tr}(\boldsymbol{W F}) * 0.052$ etc. as shown the flow scheme in Figure 1.

In order to check this approach, the woven and equivalent UD lamina properties of a series of woven specimens were analysed using the combination of Tsai's Modulus and the 3D stiffness model. In this step E and $v_{12}$ of the chosen woven ply were specified and Tsai's Modulus used to determine the other properties of the woven ply. Accuracy of predictions were then compared with experimental results.

\subsubsection{Laminate analysis}

The next step developed the method further by using CLT to build the laminate stacking sequence of a given layup and predicted the engineering constants of the laminate. This was done for both 2D and 3D representations of the laminate. Initially the transformed reduced stiffness matrix was calculated for each ply as shown below:

$$
\overline{Q_{l j}}=\left[\begin{array}{lll}
\overline{Q_{11}} & \overline{Q_{12}} & \overline{Q_{16}} \\
\overline{Q_{12}} & \overline{Q_{22}} & \overline{Q_{26}} \\
\overline{Q_{16}} & \overline{Q_{26}} & \overline{Q_{66}}
\end{array}\right]
$$


before the stiffness matrices (ABD) of the laminate were calculated as follows:

$$
A B D=\left[\begin{array}{ll}
A & B \\
B & D
\end{array}\right]\left\{\begin{array}{c}
{[A]=\sum_{k=1}^{n}\left\{\overline{Q_{\imath \jmath}}\right\}_{n}\left(z_{k}-z_{k-1}\right)} \\
{[B]=\frac{1}{2} \sum_{k=1}^{n}\left\{\overline{Q_{\imath \jmath}}\right\}_{n}\left(z_{k}^{2}-z_{k-1}^{2}\right)} \\
{[D]=\frac{1}{3} \sum_{k=1}^{n}\left\{\overline{Q_{\imath \jmath}}\right\}_{n}\left(z_{k}^{3}-z_{k-1}^{3}\right)}
\end{array}\right.
$$

where $[A]$ is the extensional stiffness matrix, $[B]$ is the bending-extension coupling stiffness, $[D]$ is the bending stiffness, $\left\{\overline{Q_{\imath \jmath}}\right\}_{n}$ is the stiffness of the nth layer and $z_{k}$ is the distance from the mid-plane to the centroid of the kth layer.

Further development of the model was needed to accommodate hybrid laminates consisting of multiple lamina types, i.e. combinations of woven and UD plies. In the case of a hybrid laminate with woven plies, the method introduced by Akkerman [18] was again used for the 3D stiffness matrix of these plies with the standard approach used for UD plies. However, the equivalent UD stiffness matrix of the woven laminate could be transformed using the same transformation matrix as would be used for the UD laminate [18]. Throughout each stage, the accuracy of the method was checked against experimental values where possible.

\subsection{Assessing omni and unit circle failure envelopes}

Omni and strain space unit circle failure envelopes were assessed by comparing their predictions with experimental test data from literature and industrial partners. The method established by Tsai [3] to generate envelopes for a given material, at $15^{\circ}$ increments, and find the inner envelope was modified slightly to accommodate hybrid laminates. The $15^{\circ}$ increment is useful if the angles within a layup are unknown and this represents the most conservative case. However, if the ply material and angle combinations within a laminate are known, it is possible to superimpose the failure envelopes and generate the inner envelope with less calculation. For example, for a [45/0/-45/90]s layup with T700 C-Ply 55 used for angled plies and IM7-977 used for 0/90 ${ }^{\circ}$ plies, only three envelopes are required to calculate the inner omni strain envelope, rather than fourteen envelopes using the $15^{\circ}$ increment method. It should be noted here that any assumptions within the chosen failure criteria, 
such as the interaction parameter in quadratic failure criteria, such as Tsai-Wu, are translated to the unit circle envelope.

\subsection{Results}

Results comparing the predicted engineering constants and experimental values from literature and/or industrial partners will be presented covering both lamina and laminate levels of analysis. These comparisons have been made without taking into account the variability of the experimental values, due to a lack of sufficient data. Failure envelope data compared with bi-axial test data from the World-Wide Failure Exercise (WWFE) or literature sources to assess the conservatism of the generated envelopes.

\subsection{Assessing Tsai’s Modulus Results}

\subsubsection{UD Specimens}

Results for the assessment of Tsai's Modulus for UD laminae are shown in Figure 2 and Figure 3. The original data presented by Tsai et al. [1] was used to generate master ply values before calculating $\mathrm{E}_{2}$ and $\mathrm{G}_{12}$ based on Tsai's Modulus, shown in Section 1.0 of the supplementary material. The error between Tsai's Modulus predicted and experimentally measured properties are shown in normalised form for ease of comparison. Further experimental data has been added to Figure 2 and Figure 3 from NIAR NCAMP [21] published materials along with some data from industrial partners. At the lamina level the Tsai's Modulus approach is capable of predicting $E_{2}$ with a maximum error of $\pm 23 \%$ and $\mathrm{G}_{12}$ with a maximum error of $\pm 45 \%$ for a given UD $E_{1}$. However, it should be noted that $\mathrm{E}_{2}$ and $\mathrm{G}_{12}$ are predicted with an accuracy of $\pm 10 \%$ for $65 \%$ and $53 \%$ of the materials in Figure 2 and Figure 3, respectively. While there is a potentially large variance in these results it is worth remembering how the coefficient of variance of the initial master ply values increased significantly with increasing matrix dominance.

The differences in predictions for $\mathrm{G}_{12}$ could be due to a number of reasons. Firstly, the choice of shear test method has an impact on the results. The Composite Materials Handbook MIL-HDBK-17-1F [23] notes that the V-notched rail shear test (ASTM D7078) is the most accurate for determining shear modulus but acceptable predictions can also be made with the $\pm 45^{\circ}$ tensile shear test, used for much of the data in Figure 2 and Figure 3 , 
including all those from NIAR. However, the $\pm 45^{\circ}$ tensile shear test does not create a pure stress state. Therefore the shear modulus extracted from test data is an effective shear modulus rather than an absolute one [23]. Secondly, the most frequently used standards (ASTM D3518/SRM 7R-94) for $\pm 45^{\circ}$ tensile shear tests recommend different regions of strain to calculate the shear modulus, 2000 to $6000 \mu \varepsilon$ and $500-3000 \mu \varepsilon$, respectively. Therefore different results will be obtained from each region [23]. These reasons can explain the high level of variance in shear modulus predictions using invariants given that the model may be trying to predict inaccurate values. It is also worth remembering that the power of Tsai's Modulus invariants is their ability to predict laminate stiffness for highly orthotropic plies. Therefore, larger errors in $E_{y}$ and $E_{s}$ are still small enough to not affect the accuracy of the prediction of the laminate stiffness. This will be investigated further in a subsequent section.

\subsubsection{Woven Specimens}

Initially a study was completed to establish the application of a combined Tsai's Modulus and the 3D compliance matrix for woven fabric composites proposed by Akkerman [18]. Table 1 shows the woven fabric and equivalent UD properties for twelve carbon fabric reinforced composites. Analysing these results, a few simple, convenient relationships could be established between woven fabric and equivalent UD composite properties. Firstly, the factor relating $\mathrm{E}_{1}{ }^{\mathrm{WF}}$ to $\mathrm{E}_{1}{ }^{\mathrm{Eqv} . U \mathrm{U}}$ was simply the division of the Tsai’s Modulus factors, $0.88 / 0.47=1.87$, where 0.88 and 0.47 were the master ply values for the UD and woven ([0/90]) type laminates, respectively. Similarly, for $\mathrm{E}_{2}$, the factor relating $\mathrm{E}_{2}{ }^{\mathrm{WF}}$ to $\mathrm{E}_{2}{ }^{\mathrm{Eqv} . \mathrm{UD}}$ was $0.052 / 0.47=0.11$ while for $v_{12}$ the factor was found to be 9.1 . Based on these factors, a reliable combined analytical method is proposed where the 3D stiffness matrix, Equation 3, could now be used to obtain engineering constants of a given woven fabric composite irrespective of Tsai's Modulus.

Results for the assessment of Tsai's Modulus invariance for woven laminae are shown in Figure 4 and Figure 5 in normalised form for ease of comparison. On this occasion there is a very low coefficient of variance in both warp $(7.9 \%)$ and weft directions $(8.4 \%)$. This is due to the similarity between the modulus and fibre content in each of these directions. This means that at the lamina level the Tsai's Modulus approach is capable of predicting $E_{2}$ with an accuracy of $\pm 5 \%$ for a given woven $E_{1}$. The prediction accuracy for $\mathrm{G}_{12}$ has improved from $\pm 45 \%$ for UD laminae to $\pm 32 \%$ for woven laminae for a given woven $\mathrm{E}_{1}$. 
As with UD laminae, the same reasons for higher shear modulus variance exist. However, other factors potentially effecting shear modulus predictions for woven specimens are weave type, matrix/resin type and tow width. In order to check the influence of these factors on master ply values the data in Table 1 was grouped by weave, test method, resin type and tow size as shown in Section 2.0 of the supplementary data. These results show that the greatest variance in master ply values were caused by resin type and tow width. This is supported in literature by Medina et al. [23] who also found that weave type did not effect in-plane shear. Firstly, resin type has a large effect on the master ply values, particularly for shear, modifying the value by $13 \%$ given that resin is very important for shear behaviour. Secondly, as tow width increases, larger, currently non-standardised, test specimens would be required for more consistent results [24].

\subsection{Laminate Results}

Table 2 shows the results for a variety of UD ply laminates using the invariants method linked with CLT. The majority of experimental data only provided $E_{x}$ and $v_{x y}$ of the laminate, so these values were compared. Tsai's Modulus was able to predict $\mathrm{E}_{\mathrm{x}}$ and $v_{\mathrm{xy}}$ of the laminate within $\pm 5 \%$ for $70 \%$ of specimens for $\mathrm{E}_{\mathrm{x}}$ and $90 \%$ of specimens for $v_{\mathrm{xy}}$, based on the master ply values of $0.88,0.052$ and 0.031 , respectively. The maximum variance was $\pm 10 \%$ and $\pm 9 \%$ respectively. The total errors for $E_{x}$ and $v_{x y}$ were both $3.7 \%$.

Table 3 presents the laminate property predictions for specimens with woven plies. Since some of the samples were from industrial partners on this work some layup information has been withheld to protect intellectual property. It should be noted that this does not compromise the work or results presented herein. As with UD ply laminates $E_{x}$ and $v_{x y}$ were compared. The Tsai's Modulus method was able to predict $\mathrm{E}_{\mathrm{x}}$ within $\pm 5 \%$ for almost half of the specimens and $v_{x y}$ within $\pm 5 \%$ for $30 \%$ of specimens. However, it should be noted here that the total number of specimens was lower than for UD ply laminates. The maximum variance was $\pm 10 \%$ for both $E_{x}$ and $v_{x y}$ respectively. Woven laminate data from an industrial partner also allowed for the comparison of $E_{y}$, $\mathrm{G}_{\mathrm{xy}}$ and $\mathrm{E}_{\mathrm{bend}}$ which had maximum variance of $\pm 6 \%, \pm 4 \%$ and $\pm 6 \%$, respectively. The total errors here for $\mathrm{E}_{\mathrm{x}}, v_{\mathrm{xy}}$ $\mathrm{E}_{\mathrm{y}}, \mathrm{G}_{\mathrm{xy}}$ and Ebend were 4.4\%, 5.3\%, 5.3\%, 4.0\% and 5.6\%, respectively. 
Table 4 presents the property predictions for hybrid laminates with highly complex combinations of 5HS, UD and non-crimp fabric (NCF) plies, thicknesses of $0.27 \mathrm{~mm}, 0.51 \mathrm{~mm}$ and $0.35 \mathrm{~mm}$ and angles of $0^{\circ}, 45^{\circ}, 90^{\circ}$, $135^{\circ}$ plies. As before layup information has been withheld to protect intellectual property. On this occasion, $\mathrm{E}_{\mathrm{x}}$, $v_{x y}, E_{y}, G_{x y}, E_{b e n d}$, and $v_{y x}$ could be compared. Results illustrate that for the five specimens studied, the maximum variance in predictions from expected values, using a combination of Tsai's Modulus, CLT and the 3D stiffness matrix for woven fabric composites [18] were $\pm 2 \%, \pm 8 \%, \pm 3 \%, \pm 7 \%, \pm 2 \%$ and $\pm 9 \%$, respectively. The total errors for $\mathrm{E}_{\mathrm{x}}, v_{\mathrm{xy}}, \mathrm{E}_{\mathrm{y}}, \mathrm{G}_{\mathrm{xy}}, \mathrm{E}_{b e n d}$, and $\mathrm{v}_{\mathrm{yx}}$ in this case were $2.6 \%,-6.2 \%, 1.7 \%, 5.5 \%, 0.9 \%,-7.8 \%$, respectively. In fact, the predictions for $E_{x}, E_{y}$, and $E_{b e n d}$, obtained from the $D$ matrix of the normalised values, were all within $5 \%$ of the expected values. These results illustrate that, although the potential error in property predictions for each constituent lamina are high, these are not transferred to the laminate. For example, the UD ply used in these hybrid laminates has an error in $\mathrm{G}_{12}$ of $+35 \%$. However, when this is incorporated into the laminate the error in $\mathrm{G}_{x y}$ reduces to just $\pm 7 \%$.

Although the relatively large variations at ply level, after Tsai's Modulus based derivations, have been noted previously, these have been shown to have little impact when it comes to the laminate. Therefore, there should be little expectation or emphasis put on initial lamina level predictions as the Tsai's Modulus approach is most applicable to highly orthotropic laminates.

\subsection{Assessing the Omni-Failure Envelope Results}

The WWFE is the main source of validation data for omni failure envelopes [19], [20]. Figure 6 shows the unit circle failure envelope in strain space and experimental test data for [0/ $\pm 45 / 90]_{\mathrm{s}}$ AS4/3501-6 laminate [3], [25], [26], depicted in stress space. Further validation is shown in Section 3.0 of the of the supplementary material.

The unit circle failure envelope is a conservative failure envelope, therefore in order to establish its conservatism, other failure criteria were added in Figure 7, still depicted in stress space. Envelopes for the maximum stress, Tsai-Hill, and Puck failure criteria were generated for the same material and layup. This established that of these criteria the unit circle was the most conservative. Of the available, valid test points, only three of thirty-one were within the unit circle. However, twice as many were within the Tsai-Hill envelope and 
three times as many for the maximum stress criteria. Developing a criteria and generating an envelope that can be conservative enough yet still give accurate predictions is challenging. Therefore, the unit circle envelope (in strain space) involves experimental measurements as anchor points which help to provide a more realistic picture.

Finally, a complex eight ply hybrid laminate with UD and woven plies was taken from Section 4.2, Table 4, Figure 8. Results for this envelope show that the woven plies are dominant and have most impact on the LPF envelope and therefore the final shape of the unit circle failure envelope. Due to a lack of experimental data, namely strain to failure of the plies for this arrangement, this envelope is purely predictive, although the approach has been proven accurate in the UD and woven specimens.

\subsection{Results Summary}

In summary, the previous results have assessed the ability of Tsai's Modulus to predict the engineering constants of different laminae and laminates. A lamina level prediction of $\mathrm{E}_{2}$ and $\mathrm{G}_{12}$ can vary considerably from the experimental data. However, the approach by which $\mathrm{G}_{12}$ experimental data is obtained may exacerbate this limitation of the method. Predictions improved with the use of the method shown by Akkerman [18] to predict engineering constants for woven fabrics using a 3D stiffness matrix developed using a cross-ply arrangement of equivalent UD properties. On this occasion the maximum variance in $\mathrm{G}_{12}$ was $\pm 32 \%$. From the analysis it appears that the potential inaccuracy in property predictions for each constituent lamina is not translated to the laminate. This is the key benefit of Tsai's Modulus invariants, accurate laminate property predictions with limited knowledge of the properties of the constituent plies.

At a laminate level, Tsai's Modulus is more capable of accurately predicting the laminate moduli as well as the major Poisson's ratio and flexural moduli. The maximum variance in prediction was $\pm 10 \%$ for $E_{x}$ and $\pm 9 \%$ for $\mathrm{v}_{\mathrm{yx}}$ even when highly complex laminates with combinations of 5HS, UD and NCF plies in a variety of stacking sequences were considered. Results have illustrated that as the complexity of the system increases, i.e. from a single lamina to a highly complex laminate, the accuracy of predictions improves. 
The strain space unit circle failure envelope has been shown to be one of the most conservative envelopes currently available. Comparisons with experimental results have been shown for both UD and woven laminates. However, the level of conservatism is not consistent across laminate types.

\subsection{Conclusions}

This work has extended the use of the Tsai's Modulus invariants method proposed by Tsai et al. [1] to include UD and woven lamina as well as including laminates with complex geometry and stacking sequences. Tsai's Modulus has been shown to be a useful tool for the initial design and selection of composite materials, particularly in predicting the engineering constants of laminates. Tsai's Modulus can provide predictions of lamina properties within $\pm 23 \%$ for $\mathrm{E}_{2}$ and $\pm 45 \%$ for $\mathrm{G}_{12}$. At the laminate level, predictions improve significantly with trace Tsai's Modulus being able to predict, $\pm 10 \%$ for $\mathrm{E}_{\mathrm{x}}, \pm 6 \%$ for $\mathrm{E}_{\mathrm{y}}, \pm 10 \%$ for $v_{\mathrm{xy}}, \pm 7 \%$ for $\mathrm{G}_{\mathrm{xy}}, \pm 9 \%$ for Ebend and $\pm 9 \%$ for $v_{\mathrm{yx}}$ respectively. Another advantage of this approach is the prediction of out-of-plane laminate properties using only limited input data at the lamina level. The strain space unit circle failure envelope has been shown to be a conservative envelope for last ply failure of both UD and woven specimens. However, the conservatism of the envelope is not consistent across materials. Future work should attempt to improve the accuracy of Tsai's Modulus at a lamina level, particularly with respect to in-plane and out-of-plane shear properties. Future work should also attempt to validate the strain space unit circle envelope with hybrid laminate biaxial test data.

\section{Acknowledgements}

This study was conducted in collaboration with Bombardier Belfast, Collins Aerospace (UK), and Hexcel as part of a Northern Ireland Advanced Engineering Competence Centre (NIAECC) programme funded by Invest Northern Ireland conducted at Northern Ireland Advanced Composites and Engineering (NIACE) Centre.

Significant contribution and knowledge transfer from Professor Stephen W. Tsai and the team at Stanford University is also gratefully acknowledged.

\section{References}

[1] S. W. Tsai and J. D. D. Melo, “An invariant-based theory of composites,” Compos. Sci. Technol., vol. 
100, pp. 237-243, 2014, doi: 10.1016/j.compscitech.2014.06.017.

[2] S. W. Tsai, S. Sihn, and J. D. D. Melo, "Trace-based stiffness for a universal design of carbon-fiber reinforced composite structures,” Compos. Sci. Technol., vol. 118, pp. 23-30, 2015, doi: 10.1016/j.compscitech.2015.08.003.

[3] S. W. Tsai and J. D. D. Melo, “A unit circle failure criterion for carbon fiber reinforced polymer composites," Compos. Sci. Technol., vol. 123, pp. 71-78, 2016, doi: 10.1016/j.compscitech.2015.12.011.

[4] J. D. D. Melo, J. Bi, and S. W. Tsai, “A novel invariant-based design approach to carbon fiber reinforced laminates," Compos. Struct., vol. 159, pp. 44-52, 2017, doi: 10.1016/j.compstruct.2016.09.055.

[5] A. Arteiro et al., "A case for Tsai's Modulus, an invariant-based approach to stiffness," Compos. Struct., vol. 252, no. June, p. 112683, 2020, doi: 10.1016/j.compstruct.2020.112683.

[6] A. Arteiro, L. F. Pereira, M. A. Bessa, C. Furtado, and P. P. Camanho, “A micro-mechanics perspective to the invariant-based approach to stiffness," Compos. Sci. Technol., vol. 176, no. April, pp. 72-80, 2019, doi: 10.1016/j.compscitech.2019.04.002.

[7] L. Li, V. V. Volovoi, and D. H. Hodges, “Cross-sectional design of composite rotor blades,” J. Am. Helicopter Soc., vol. 53, no. 3, pp. 240-251, 2008, doi: 10.4050/JAHS.53.240.

[8] R. Ganguli and I. Chopra, "Aeroelastic optimization of a helicopter rotor with composite coupling," J. Aircr., vol. 32, no. 6, pp. 1326-1334, 1995, doi: 10.2514/3.46882.

[9] S. Murugan and R. Ganguli, "Aeroelastic stability enhancement and vibration suppression in a composite helicopter rotor,” J. Aircr., vol. 42, no. 4, pp. 1013-1024, 2005, doi: 10.2514/1.5652.

[10] S. W. Tsai, N. Sharma, A. Arteiro, S. Roy, and B. Rainsberger, Composite double-double and grid/skin structures, 1st ed. Composites Design Group, Aeronautics \& Astronautics Department, Stanford University, 2019.

[11] C. Hochard, J. Payan, and O. Montagnier, "Design and computation of laminated composite structures," Compos. Sci. Technol., vol. 65, no. 3-4, pp. 467-474, 2005, doi: 10.1016/j.compscitech.2004.09.013. 
[12] J. P. Blasques and M. Stolpe, "Maximum stiffness and minimum weight optimization of laminated composite beams using continuous fiber angles," Struct. Multidiscip. Optim., vol. 43, no. 4, pp. 573-588, 2011, doi: 10.1007/s00158-010-0592-9.

[13] S. K. Ha and C. A. Cimini, "Theory and validation of the master ply concept for invariant-based stiffness of composites,” J. Compos. Mater., vol. 52, no. 12, pp. 1699-1708, 2018, doi: $10.1177 / 0021998317728782$.

[14] P.-W. Gerbaud, F. Otero, P. Bussetta, and P. P. Camanho, “An invariant based transversely-isotropic constitutive model for unidirectional fibre reinforced composites considering the matrix viscous effects," Mech. Mater., vol. 138, no. July, p. 103146, 2019, doi: 10.1016/j.mechmat.2019.103146.

[15] P. Chaphalkar and A. D. Kelkar, "Classical laminate theory model for twill weave fabric composites," Compos. - Part A Appl. Sci. Manuf., vol. 32, no. 9, pp. 1281-1289, 2001, doi: 10.1016/S1359$835 \mathrm{X}(01) 00101-4$

[16] J. Gao et al., "A multi-scale method for predicting ABD stiffness matrix of single-ply weave-reinforced composite," Compos. Struct., vol. 230, no. March, p. 111478, 2019, doi: 10.1016/j.compstruct.2019.111478.

[17] I. S. Raju and J. T. Wang, "Classical laminate theory models for woven fabric composites," J. Compos. Technol. Res., vol. 16, no. 4, pp. 289-303, 1994, doi: 10.1520/ctr10589j.

[18] R. Akkerman, "Laminate mechanics for balanced woven fabrics," Compos. Part B Eng., vol. 37, no. 2-3, pp. 108-116, 2005, doi: 10.1016/j.compositesb.2005.08.004.

[19] P. D. Soden, M. J. Hinton, and A. S. Kaddour, "Lamina properties, lay-up configurations and loading conditions for a range of fibre reinforced composite laminates," Fail. Criteria Fibre-Reinforced-Polymer Compos., vol. 58, pp. 30-51, 2004, doi: 10.1016/B978-008044475-8/50003-2.

[20] P. D. Soden, M. J. Hinton, and A. S. Kaddour, "Biaxial test results for strength and deformation of a range of E-glass and carbon fibre reinforced composite laminates. Failure exercise benchmark data," 
Fail. Criteria Fibre-Reinforced-Polymer Compos., vol. 62, pp. 52-96, 2004, doi: 10.1016/B978008044475-8/50004-4.

[21] Wichita State University, "National Center for Advanced Materials Performance," 2020. https://www.wichita.edu/research/NIAR/Research/ncamp.php (accessed Jan. 27, 2020).

[22] S. W. Tsai and J. D. D. Melo, Composite Materials Design and Testing, 1st ed. Composites Design Group, 2015.

[23] C. Medina, C. Canales, C. Arango, and P. Flores, "The influence of carbon fabric weave on the in-plane shear mechanical performance of epoxy fiber-reinforced laminates,” J. Compos. Mater., vol. 48, no. 23, pp. 2871-2878, 2014, doi: 10.1177/0021998313503026.

[24] Department Of Defence, MIL-HDBK-17-1F - Polymer Matrix Composites Guidelines for Characterization of Structural Materials, vol. 1, no. June. 2002.

[25] V. P. Rajan and W. A. Curtin, "Rational design of fiber-reinforced hybrid composites: A global load sharing analysis,” Compos. Sci. Technol., vol. 117, pp. 199-207, 2015, doi:

10.1016/j.compscitech.2015.06.015.

[26] D. Quinn, M. Price, and A. Murphy, "Influence of Boundary Conditions on the Low Velocity Impact Damage of Carbon Fibre Reinforced Plastic Plates,” in ICTWS 2014 7th International Conference on Thin-Walled Structures, 2014, pp. 1-8.

[27] R. Muñoz, S. Delgado, C. González, B. López-Romano, D. Y. Wang, and J. Llorca, "Modeling lightning impact thermo-mechanical damage on composite materials," Appl. Compos. Mater., vol. 21, no. 1, pp. 149-164, 2014, doi: 10.1007/s10443-013-9377-9.

[28] D. Dalli, G. Catalanotti, L. F. Varandas, B. G. Falzon, and S. Foster, "Mode I intralaminar fracture toughness of 2D woven carbon fibre reinforced composites: A comparison of stable and unstable crack propagation techniques,” Eng. Fract. Mech., vol. 214, no. March, pp. 427-448, 2019, doi: 10.1016/j.engfracmech.2019.04.003. 
Table 1 - Comparison of woven lamina and equivalent UD properties

\begin{tabular}{|c|c|c|c|c|c|c|c|c|c|}
\hline & \multicolumn{4}{|c|}{ Woven Properties } & & \multicolumn{4}{|c|}{ Eqv. UD Properties } \\
\hline & $\begin{array}{l}\mathrm{Ex}^{\mathrm{WF}} \\
(\mathrm{GPa})\end{array}$ & $\begin{array}{l}\mathrm{Ey}^{\mathrm{WF}} \\
(\mathrm{GPa})\end{array}$ & $\begin{array}{c}v_{12} \mathrm{WF} \\
(-)\end{array}$ & $\begin{array}{l}\mathrm{G}_{12} \mathrm{WF} \\
(\mathrm{GPa})\end{array}$ & $\begin{array}{l}\text { Tsai's } \\
\text { Modulus } \\
(\mathrm{GPa})\end{array}$ & $\begin{array}{l}\mathrm{Ex}^{\mathrm{UD}} \\
(\mathrm{GPa})\end{array}$ & $\begin{array}{l}\mathrm{Ey}^{\mathrm{UD}} \\
(\mathrm{GPa})\end{array}$ & $\begin{array}{c}v_{12} \mathrm{UD} \\
(-)\end{array}$ & $\begin{array}{l}\mathrm{G}_{12} \mathrm{UD} \\
(\mathrm{GPa})\end{array}$ \\
\hline $\begin{array}{c}\text { Toray T300B/GE Ultem1000 } \\
\text { 5HS [18] }\end{array}$ & 60.0 & 60.0 & 0.050 & 4.5 & 127.7 & 112.4 & 6.6 & 0.45 & 4.0 \\
\hline $\begin{array}{c}2 \times 2 \text { twill G0986-6K HT5131 } \\
{[27]}\end{array}$ & 70.0 & 70.0 & 0.020 & 5.0 & 148.9 & 131.0 & 7.7 & 0.18 & 4.6 \\
\hline Hexcel 8552 AS4 3K PW* & 66.1 & 66.6 & 0.050 & 5.0 & 140.6 & 123.7 & 7.3 & 0.45 & 4.4 \\
\hline $\begin{array}{c}\text { Tencate TC250-HTS40 12k PW } \\
{[28]}\end{array}$ & 59.7 & 59.2 & 0.040 & 3.6 & 127.0 & 111.8 & 6.6 & 0.36 & 3.9 \\
\hline Tencate 12K HTS40 SFP PW* & 61.6 & 61.2 & 0.040 & 3.6 & 131.1 & 115.4 & 6.8 & 0.36 & 4.1 \\
\hline $\begin{array}{c}\text { AS4C 3k-TenCate BT250E-6 } \\
\text { PW* }\end{array}$ & 59.0 & 58.8 & 0.055 & 4.0 & 125.5 & 110.4 & 6.5 & 0.49 & 3.9 \\
\hline Toray TR305/HS0838 2x2 twill & 68.6 & 67.4 & 0.040 & 3.9 & 146.0 & 128.5 & 7.6 & 0.36 & 4.5 \\
\hline T300-6K FiberCote E-765 5HS & 64.4 & 62.7 & 0.047 & 3.8 & 137.0 & 120.6 & 7.1 & 0.45 & 4.2 \\
\hline T650/7740 3K 8HS Fiberite & 68.6 & 67.8 & 0.050 & 4.3 & 146.0 & 128.5 & 7.6 & 0.45 & 4.5 \\
\hline T300/5208 8HS & 67.6 & 64.8 & 0.053 & 5.0 & 143.8 & 126.5 & 7.5 & 0.48 & 4.5 \\
\hline T650-35/CYCOM 5320 8HS & 69.1 & 68.3 & 0.048 & 5.6 & 147.0 & 129.4 & 7.6 & 0.43 & 4.6 \\
\hline $\begin{array}{c}\text { Gurit SE 84LV-RC200T 3k } 2 \times 2 \\
\text { Twill [28] }\end{array}$ & 60.6 & 61.6 & 0.04 & 5.0 & 128.9 & 113.5 & 6.7 & 0.36 & 4.0 \\
\hline
\end{tabular}

* material data taken from NIAR repository 
Table 2 - Laminate property predictions for specimens with UD plies

\begin{tabular}{|c|c|c|c|c|c|c|c|c|}
\hline Material & Layup & $\begin{array}{l}\text { Ply Thick. } \\
\text { (mm) }\end{array}$ & $\begin{array}{l}\text { Ex Pred. } \\
(\mathrm{GPa})\end{array}$ & $\begin{array}{l}\text { Ex Exp. } \\
(\mathrm{GPa})\end{array}$ & $\begin{array}{l}\text { Ex Error } \\
(\%)\end{array}$ & $\begin{array}{c}v_{12} \\
\text { Pred. } \\
(-)\end{array}$ & $\begin{array}{c}v_{12} \\
\text { Exp. } \\
(-) \\
\end{array}$ & $\begin{array}{c}v_{12} \text { Error } \\
(\%)\end{array}$ \\
\hline \multirow[t]{3}{*}{ IM7/MTM45-1* } & {$[0 / 90]_{4 \mathrm{~s}}$} & 0.1397 & 80.8 & 77.2 & 4.7 & - & - & - \\
\hline & {$[45 / 0 /-45 / 90]_{3 \mathrm{~s}}$} & 0.1397 & 57.9 & 55.2 & 4.9 & - & - & - \\
\hline & {$[0 / 0 / 45 / 0 / 90 /-45 / 0 / 45 / 0 /-45]_{\mathrm{s}}$} & 0.1397 & 89.2 & 84.5 & 5.6 & - & - & - \\
\hline \multirow[t]{4}{*}{ IM7G/EP2202* } & {$[45 / 0 /-45 / 90]_{2 \mathrm{~s}}$} & 0.1829 & 60.1 & 57.0 & 5.4 & - & - & - \\
\hline & {$[45 /-45 / 0 / 45 /-45 / 90 / 45 /-45 / 45 /-45]_{\mathrm{s}}$} & 0.1829 & 38.8 & 35.9 & 8.1 & - & - & - \\
\hline & {$[0 / 45 / 0 / 90 / 0 /-45 / 0 / 45 / 0 /-45]_{\mathrm{s}}$} & 0.1829 & 92.4 & 90.7 & 1.9 & - & - & - \\
\hline & {$[90 / 0 / 90]_{5}$} & 0.1829 & 58.9 & 53.7 & 9.7 & - & - & - \\
\hline IM7/BT250E-6* & {$[90 / 0 / 90]_{7}$} & 0.1473 & 52.2 & 52.0 & 0.4 & - & - & - \\
\hline Cross-ply Specimen*** & {$\left[0 / 90 / 0_{8} / 90 / 0\right]$} & 0.2867 & 114.3 & 114.4 & -0.1 & - & - & - \\
\hline IM7/CYCOM 5320-1* & {$[45 / 0 /-45 / 90]$} & 0.137 & 60.0 & 59.2 & 1.4 & - & - & 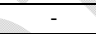 \\
\hline \multirow[t]{4}{*}{ AS4/8552* } & {$[0 / 90]_{2 \mathrm{~s}}$} & 0.188 & 70.4 & 69.2 & 1.7 & - & - & - \\
\hline & {$[45 / 0 /-45 / 90]_{2 \mathrm{~s}}$} & 0.188 & 50.5 & 48.8 & 3.5 & 0.31 & 0.30 & 3.3 \\
\hline & {$[45 /-45 / 0 / 45 /-45 / 90 / 45 /-45 / 45 /-45]_{\mathrm{s}}$} & 0.188 & 32.7 & 31.5 & 3.8 & 0.55 & 0.53 & 3.8 \\
\hline & {$[0 / 45 / 0 / 90 / 0 /-45 / 0 / 45 / 0 /-45]_{\mathrm{s}}$} & 0.188 & 77.8 & 74.0 & 5.1 & 0.43 & 0.43 & 0.0 \\
\hline \multirow[t]{4}{*}{ AS4/MTM45-1* } & {$[0 / 90]_{4 \mathrm{~s}}$} & 0.1397 & 67.9 & 67.8 & 0.1 & 0.04 & 0.03 & 2.9 \\
\hline & {$[45 / 0 /-45 / 90]_{3 \mathrm{~s}}$} & 0.1397 & 48.7 & 47.9 & 1.7 & 0.31 & 0.30 & 3.3 \\
\hline & {$[45 /-45 / 0 / 45 /-45 / 90 / 45 /-45 / 45 /-45]_{\mathrm{s}}$} & 0.1397 & 31.5 & 29.2 & 7.9 & 0.55 & 0.54 & 1.9 \\
\hline & {$[0 / 0 / 45 / 0 / 90 /-45 / 0 / 45 / 0 /-45]_{\mathrm{s}}$} & 0.1397 & 75.0 & 73.3 & 2.3 & 0.42 & 0.39 & 7.9 \\
\hline \multirow[t]{5}{*}{$\begin{array}{c}\text { Tenax-E HTS40 F13 } \\
\text { 12K 800tex/MTM45-1* }\end{array}$} & {$[0 / 90]_{4 \mathrm{~s}}$} & 0.1397 & 68.8 & 67.9 & 1.3 & 0.04 & 0.04 & 0.0 \\
\hline & {$[45 / 0 /-45 / 90]_{3 \mathrm{~s}}$} & 0.1397 & 49.4 & 47.8 & 3.3 & 0.31 & 0.34 & -8.5 \\
\hline & {$[45 /-45 / 0 / 45 /-45 / 90 / 45 /-45 / 45 /-45]_{\mathrm{s}}$} & 0.1397 & 31.9 & 31.6 & 1.1 & 0.55 & 0.56 & -1.2 \\
\hline & {$[0 / 0 / 45 / 0 / 90 /-45 / 0 / 45 / 0 /-45]_{\mathrm{s}}$} & 0.1397 & 71.7 & 77.1 & -7.0 & 0.40 & 0.43 & -7.9 \\
\hline & Total Error(s) & & & & 3.7 & 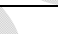 & & 3.7 \\
\hline
\end{tabular}

*material data taken from NIAR repository

**material data supplied by industrial partners 
Table 3 - Laminate property predictions for specimens with woven plies

\begin{tabular}{|c|c|c|c|c|c|c|c|c|c|c|c|c|c|c|c|c|c|}
\hline Material & Layup & $\begin{array}{c}\begin{array}{c}\text { Ply } \\
\text { Thick. } \\
\text { (mm) }\end{array}\end{array}$ & $\begin{array}{l}\text { Ex Pred. } \\
(\mathrm{GPa})\end{array}$ & $\begin{array}{l}\text { Ex Exp. } \\
\text { (GPa) }\end{array}$ & $\begin{array}{l}\text { Ex Error } \\
(\%)\end{array}$ & $\begin{array}{c}v_{12} \\
\text { Pred. } \\
(-)\end{array}$ & $\begin{array}{c}v_{12} \\
\text { Exp. } \\
(-)\end{array}$ & $\begin{array}{c}v_{12} \\
\text { Error } \\
(\%)\end{array}$ & & & & & & $\theta$ & & & \\
\hline \multirow[t]{3}{*}{$\begin{array}{c}\text { G40-500/MTM45- } \\
1 *\end{array}$} & {$[45 / 0 /-45 / 90]_{2 \mathrm{~s}}$} & 0.2007 & 46.03 & 43.78 & 5.1 & - & - & - & & & & & & & & & \\
\hline & {$[45 /-45 / 0 / 45 /-45]_{2 \mathrm{~s}}$} & 0.2007 & 29.68 & 27.72 & 7.1 & - & - & - & & & & 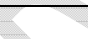 & & & & & \\
\hline & {$\left[0_{3} / 45 / 0_{3} /-45 / 0_{3} / 45 / 0_{3}\right]$} & 0.2007 & 56.75 & 55.57 & 2.1 & - & - & - & & & & $x_{1}$ & & & & & \\
\hline Cross-Ply Fabric** & {$[0 / 90]_{6}$} & 0.2360 & 55.44 & 55.2 & 0.4 & - & - & - & & 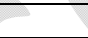 & 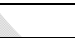 & +2 & & & & & \\
\hline \multirow[t]{3}{*}{ AS4/8552* } & {$[45 / 0 /-45 / 90]_{2 s}$} & 0.1981 & 47.23 & 46.95 & 0.6 & 0.31 & 0.32 & -1.3 & & & 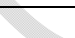 & 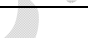 & & & & & \\
\hline & {$[45 /-45 / 0 / 45 /-45 / 45 /-45 / 90 / 45 /-45]_{\mathrm{s}}$} & 0.1981 & 30.53 & 31.23 & -2.2 & 0.56 & 0.53 & 5.7 & 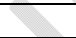 & & & $\bar{m}$ & & & & & \\
\hline & $\begin{array}{c}{[0 / 90 / 0 / 45 / 90 / 0 / 90 /-} \\
45 / 90 / 0 / 90 / 45 / 0 / 90 / 0] \\
\end{array}$ & 0.1981 & 59.43 & 58.81 & 1.1 & 0.14 & 0.14 & 0.7 & & & & & & & & & \\
\hline \multirow[t]{3}{*}{$\begin{array}{l}\text { TCAC12k-HTS40 } \\
\text { Fabric* } \\
\end{array}$} & {$[45 / 0 /-45 / 90]_{2 \mathrm{~s}}$} & 0.2159 & 44.17 & 40.33 & 9.5 & - & - & & & & & & & & & & \\
\hline & {$[45 /-45 / 0 / 45 /-45 / 45 /-45 / 90 / 45 /-45]_{\mathrm{s}}$} & 0.2159 & 28.53 & 26.34 & 8.3 & - & - & - & & 2 & & & & & & & \\
\hline & $\begin{array}{c}0 / 90 / 0 / 45 / 90 / 0 / 90 /- \\
45 / 90 / 0 / 90 / 45 / 0 / 90 / 0]\end{array}$ & 0.2159 & 55.57 & 52.81 & 5.2 & - & - & 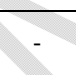 & & & & & & & & & \\
\hline $\begin{array}{c}\text { T650/CYCOM } \\
5320-18 \mathrm{HS}^{*}\end{array}$ & {$[45 / 0 /-45 / 90]$} & 0.3683 & 49.36 & 49.09 & 0.6 & - & - & - & & & & & & & & & \\
\hline Material & Layup & $\begin{array}{c}\text { Ply } \\
\text { Thick. } \\
\text { (mm) }\end{array}$ & $\begin{array}{l}\text { Ex Pred. } \\
\text { (GPa) }\end{array}$ & $\begin{array}{l}\text { Ex Exp. } \\
\text { (GPa) }\end{array}$ & $\begin{array}{l}\text { Ex Error } \\
(\%)\end{array}$ & $\begin{array}{c}v_{12} \\
\text { Pred. } \\
(-)\end{array}$ & $\begin{array}{c}v_{12} \\
\text { Exp. } \\
(-)\end{array}$ & $\begin{array}{c}v_{12} \\
\text { Error } \\
(\%)\end{array}$ & $\begin{array}{c}\text { Ey } \\
\text { Pred. } \\
(\mathrm{GPa})\end{array}$ & $\begin{array}{c}\text { Ey } \\
\text { Exp. } \\
\text { (GPa) }\end{array}$ & $\begin{array}{c}\text { Ey } \\
\text { Error } \\
(\%)\end{array}$ & $\begin{array}{c}\text { Gxy } \\
\text { Pred. } \\
\text { (GPa) }\end{array}$ & $\begin{array}{c}\text { Gxy } \\
\text { Exp. } \\
\text { (GPa) }\end{array}$ & $\begin{array}{c}\text { Gxy } \\
\text { Error } \\
(\%)\end{array}$ & $\begin{array}{l}\text { Ebend } \\
\text { Pred. } \\
\text { (GPa) }\end{array}$ & $\begin{array}{c}\text { Ebend } \\
\text { Exp. } \\
\text { (GPa) }\end{array}$ & $\begin{array}{c}\text { Ebend } \\
\text { Error } \\
(\%)\end{array}$ \\
\hline \multirow{5}{*}{$5 \mathrm{HS} * *$} & \multirow{4}{*}{$\begin{array}{l}\text { Complex combinations of } \\
0^{\circ}, 45^{\circ}, 90^{\circ}, 135^{\circ} \text { plies** }\end{array}$} & 0.3810 & 54.66 & 51.47 & 6.2 & 0.240 & 0.218 & 10.09 & 54.66 & 51.47 & 6.20 & 13.50 & 13.04 & 3.53 & 55.94 & 52.64 & 6.27 \\
\hline & & 0.3810 & 50.19 & 47.26 & 6.2 & 0.305 & 0.282 & 8.16 & 49.91 & 47.26 & 5.61 & 16.35 & 15.73 & 3.94 & 54.61 & 51.41 & 6.22 \\
\hline & & 0.3810 & 39.37 & 37.36 & 5.4 & 0.456 & 0.433 & 5.31 & 39.13 & 37.36 & 4.74 & 22.04 & 21.12 & 4.36 & 37.44 & 35.69 & 4.90 \\
\hline & & 0.3810 & 42.74 & 40.56 & 5.4 & 0.406 & 0.384 & 5.73 & 42.74 & 40.56 & 5.37 & 20.33 & 19.51 & 4.20 & 31.98 & 30.45 & 5.02 \\
\hline & Total Error(s) & & & 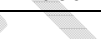 & 4.4 & & & 5.3 & & & 5.5 & & & 4.0 & & & 5.6 \\
\hline
\end{tabular}

*material data taken from NIAR repository

**material data supplied by industrial partners 
Table 4 - Laminate property predictions for hybrid laminates

\begin{tabular}{|c|c|c|c|c|c|c|c|c|c|c|c|c|c|c|c|c|c|c|c|c|}
\hline Material & Layup & $\underset{(\mathrm{mm})}{\mathrm{t}}$ & $\begin{array}{l}\text { Ex } \\
\text { Pred. } \\
(\mathrm{GPa})\end{array}$ & $\begin{array}{l}\text { Ex Exp. } \\
\text { (GPa) }\end{array}$ & $\begin{array}{l}\text { Ex } \\
\text { Error } \\
(\%)\end{array}$ & $\begin{array}{c}v_{12} \\
\text { Pred. } \\
(-)\end{array}$ & $\begin{array}{c}v_{12} \\
\text { Exp. } \\
(-)\end{array}$ & $\begin{array}{c}v_{12} \\
\text { Error } \\
(\%)\end{array}$ & $\begin{array}{l}\text { Ey } \\
\text { Pred. } \\
(\mathrm{GPa})\end{array}$ & $\begin{array}{c}\text { Ey } \\
\text { Exp. } \\
(\mathrm{GPa})\end{array}$ & $\begin{array}{c}\text { Ey } \\
\text { Error } \\
(\%)\end{array}$ & $\begin{array}{l}\mathrm{G}_{\mathrm{xy}} \\
\text { Pred. } \\
\text { (GPa) }\end{array}$ & $\begin{array}{l}\mathrm{G}_{\mathrm{xy}} \\
\text { Exp. } \\
\text { (GPa) }\end{array}$ & $\begin{array}{c}\text { Gxy } \\
\text { Error } \\
(\%)\end{array}$ & $\begin{array}{l}E_{\text {bend }} \\
\text { Pred. } \\
\text { (GPa) }\end{array}$ & $\begin{array}{l}\text { Ebend } \\
\text { Exp. } \\
\text { (GPa) }\end{array}$ & $\begin{array}{c}\text { Ebend } \\
\text { Error } \\
(\%)\end{array}$ & $\begin{array}{c}v_{21} \\
\text { Pred. } \\
(-)\end{array}$ & $\begin{array}{c}v_{21} \\
\text { Exp. } \\
(-)\end{array}$ & $\begin{array}{c}v_{21} \\
\text { Error } \\
(\%)\end{array}$ \\
\hline \multirow{6}{*}{$\begin{array}{c}5 \mathrm{HS} / \mathrm{UD} / \\
\mathrm{NCF}\end{array}$} & \multirow{5}{*}{$\begin{array}{l}\text { Complex combinations of } \\
0^{\circ}, 45^{\circ}, 90^{\circ}, 135^{\circ} \text { plies in layups } \\
\text { of } 8,14,48 \text { and } 31 \text { plies** }\end{array}$} & $\begin{array}{c}0.35 / \\
0.27 / \\
0.51\end{array}$ & 80.07 & 79.3 & 0.97 & 0.23 & 0.25 & -6.40 & 56.3 & 55.8 & 0.95 & 16.6 & 15.6 & 6.47 & 60.4 & 59.6 & 1.41 & 0.16 & 0.174 & -8.05 \\
\hline & & $\begin{array}{c}0.35 / \\
0.27 / \\
0.51\end{array}$ & 92.1 & 90.5 & 1.75 & 0.51 & 0.54 & -6.48 & 31.8 & 30.9 & 2.85 & 20.5 & 19.6 & 4.34 & 103.6 & 103 & 0.53 & 0.17 & 0.183 & -7.10 \\
\hline & & $\begin{array}{c}0.35 / \\
0.27 / \\
0.51 \\
\end{array}$ & 100.38 & 99 & 1.39 & 0.44 & 0.46 & -5.43 & 33.2 & 32.6 & 1.96 & 18.6 & 17.6 & 5.45 & 100.2 & 98.9 & 1.32 & 0.14 & 0.153 & -8.50 \\
\hline & & $\begin{array}{c}0.35 / \\
0.27 / \\
0.51\end{array}$ & 78.56 & 77.6 & 1.24 & 0.31 & 0.34 & -7.65 & 51.2 & 50.3 & 1.69 & 20.4 & 19.5 & 4.82 & 73.2 & 72.1 & 1.50 & 0.200 & 0.217 & -7.83 \\
\hline & & $\begin{array}{c}0.35 / \\
0.27 / \\
0.51 \\
\end{array}$ & 80.0 & 79.3 & 0.84 & 0.23 & 0.25 & $\begin{array}{l}-5.26 \\
\end{array}$ & 56.4 & 55.8 & 1.04 & 16.6 & 15.6 & 6.60 & 60.4 & 59.6 & 1.36 & 0.16 & 0.173 & -7.51 \\
\hline & Total Error(s) & & & & 2.6 & & & -6.2 & & & 1.7 & & & 5.5 & & & 0.9 & & & -7.8 \\
\hline
\end{tabular}

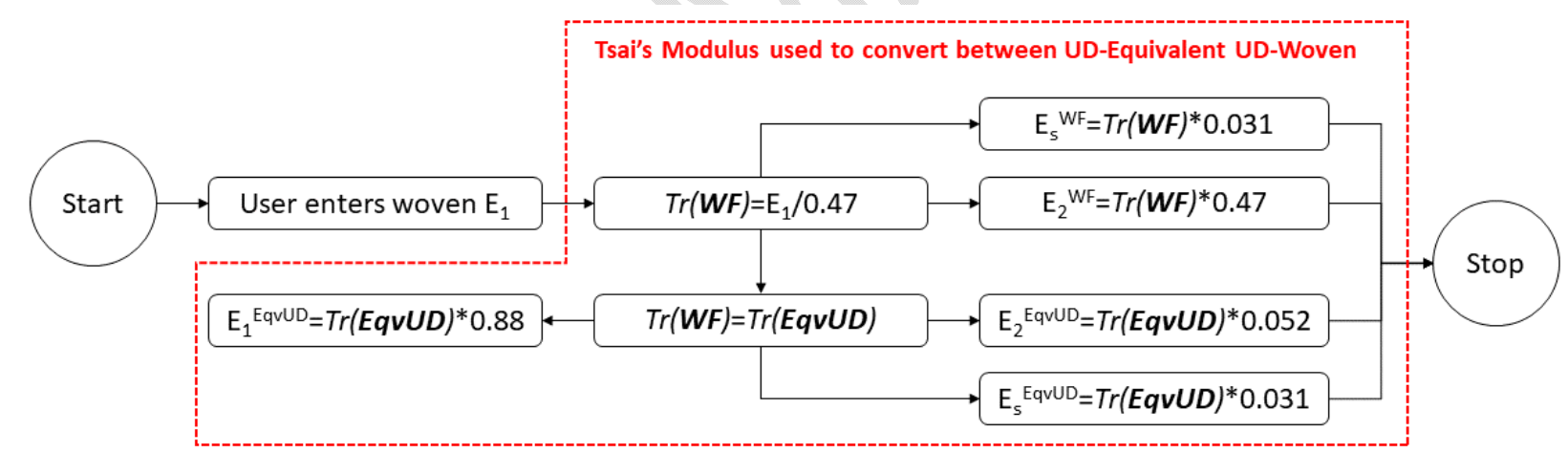

where $\operatorname{Tr}(\boldsymbol{W F})$ and $\operatorname{Tr}(E q v U D)$ are the Tsai's Moduli of the woven and equivalent UD matrices, $E_{1}$ EqvUD, $E_{2}$ EqvuD and $E_{s}{ }^{E q v U D}$ are the longitudinal, transverse and shear moduli of the equivalent UD matrix and $E_{2}{ }^{W F}$ and $E_{s}$ WF are the transverse and shear modulus of the woven matrix.

Figure 1 - Flow scheme for woven/eqv. UD property calculation 


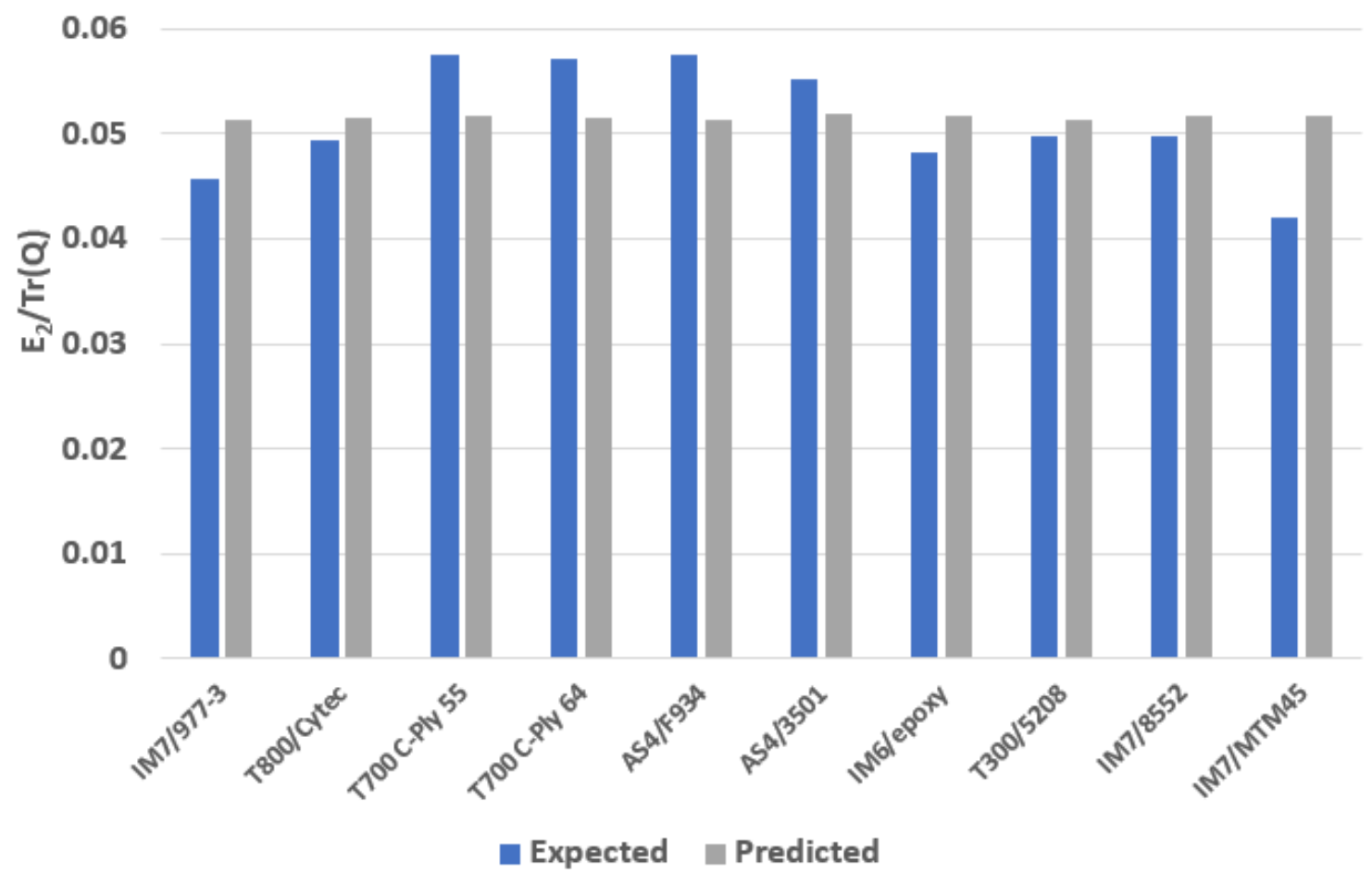

Figure 2 - Graphical comparison of normalised predicted E2 with experimental values for UD laminae

0.05

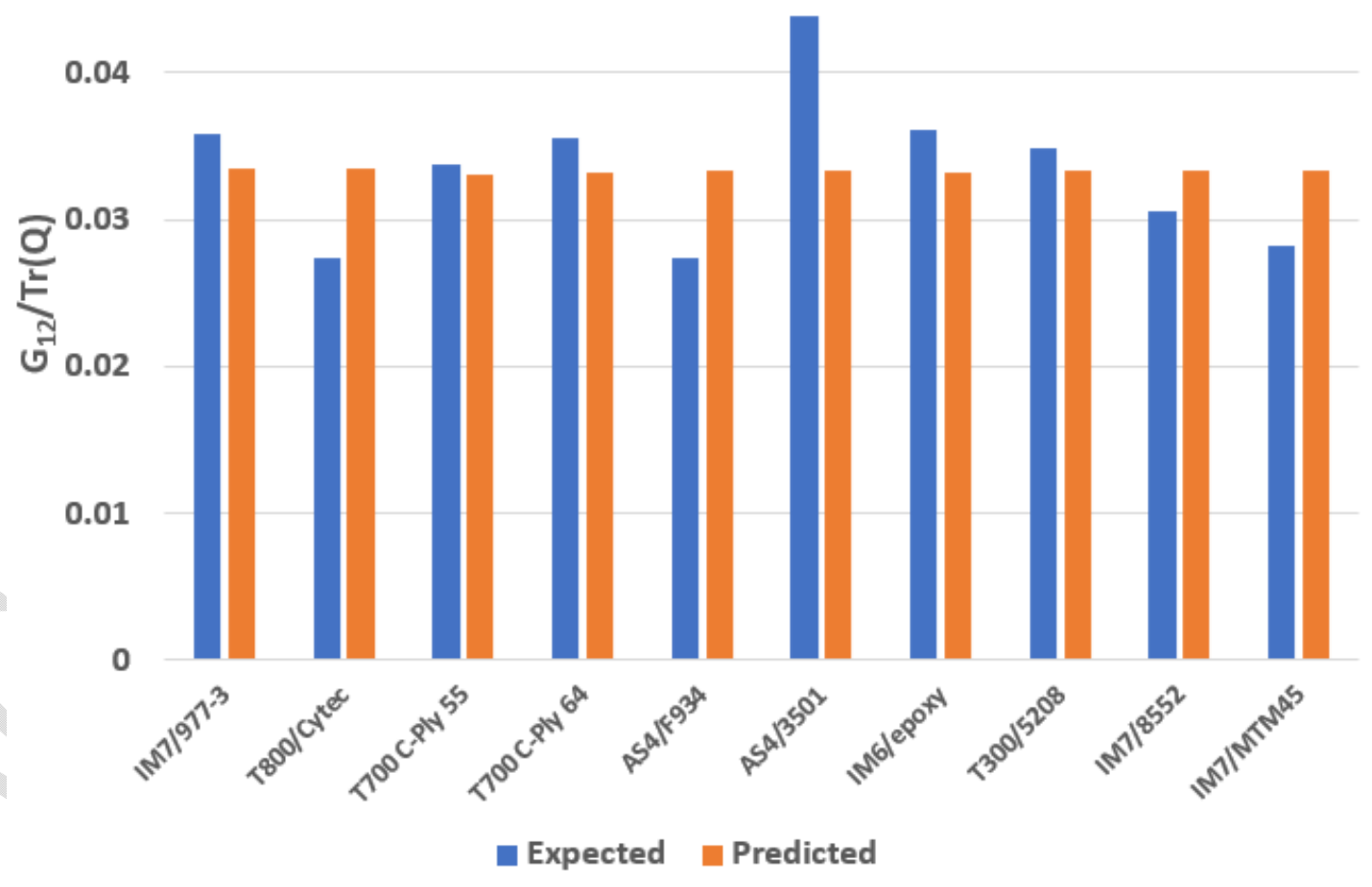

Figure 3 - Graphical comparison of normalised predicted $G_{12}$ with experimental values for UD laminae 


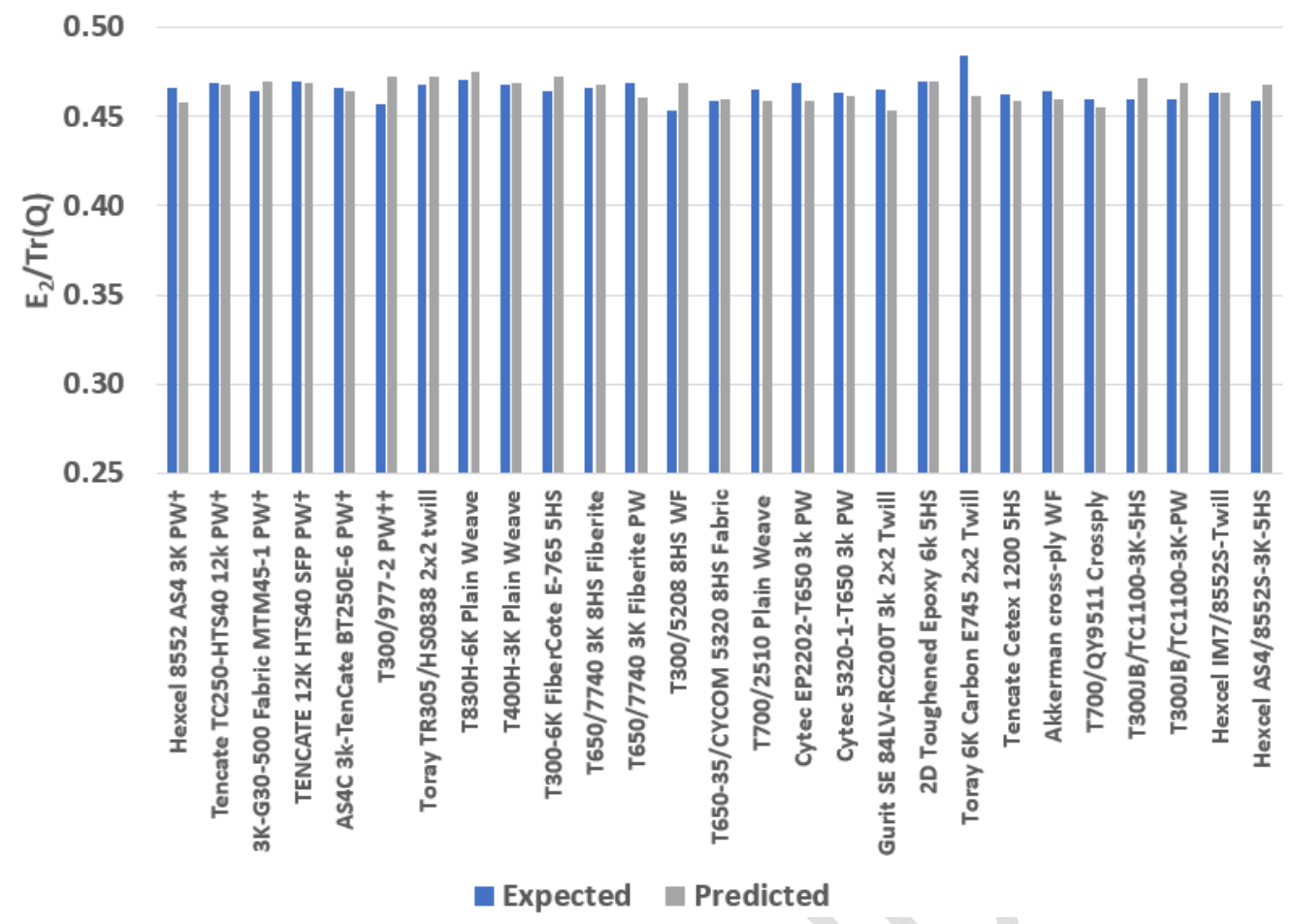

Figure 4 - Graphical comparison of normalised predicted $E_{2}$ with experimental values for woven laminae

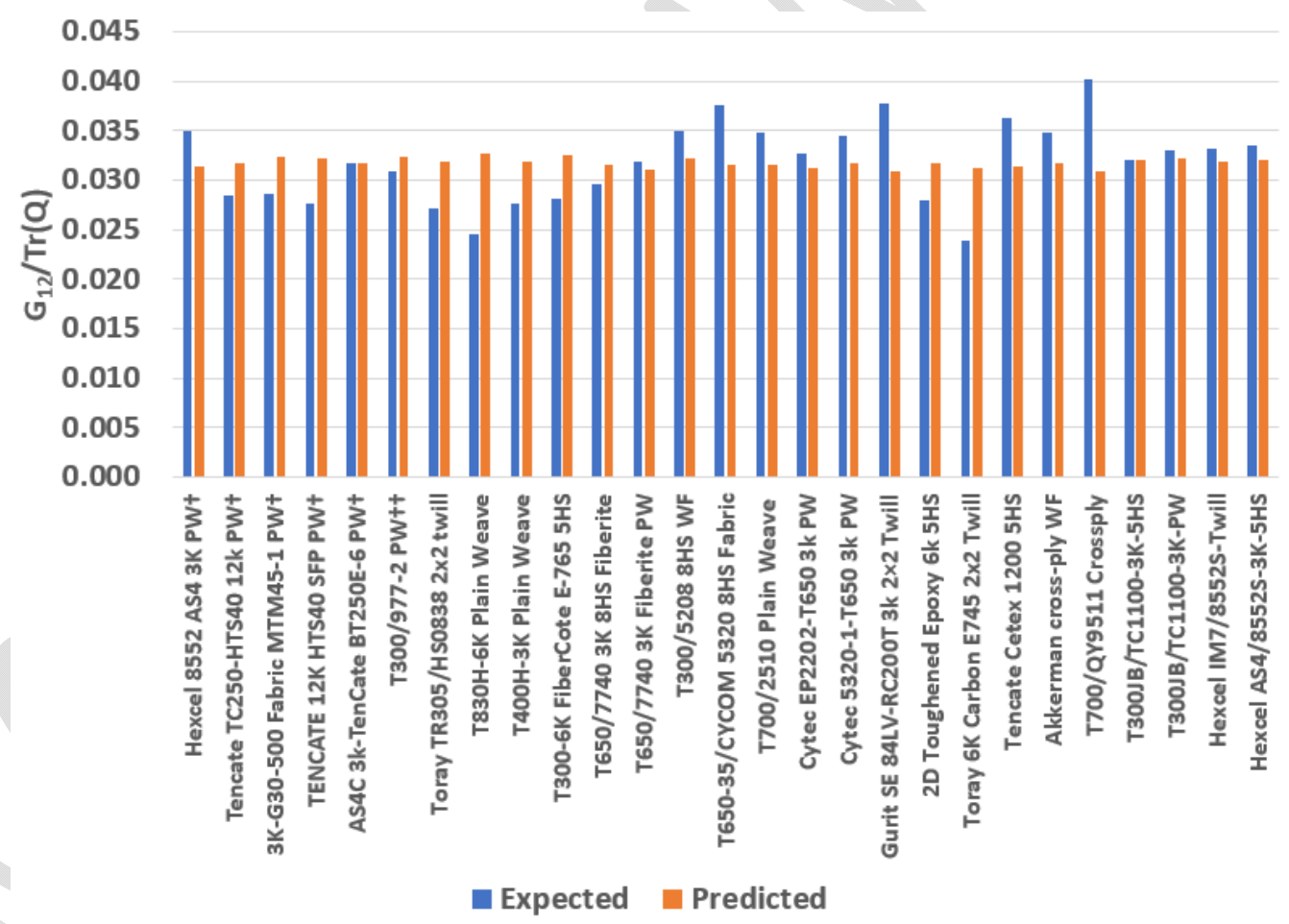

Figure 5 - Graphical comparison of normalised predicted $G_{12}$ with experimental values for woven laminae 


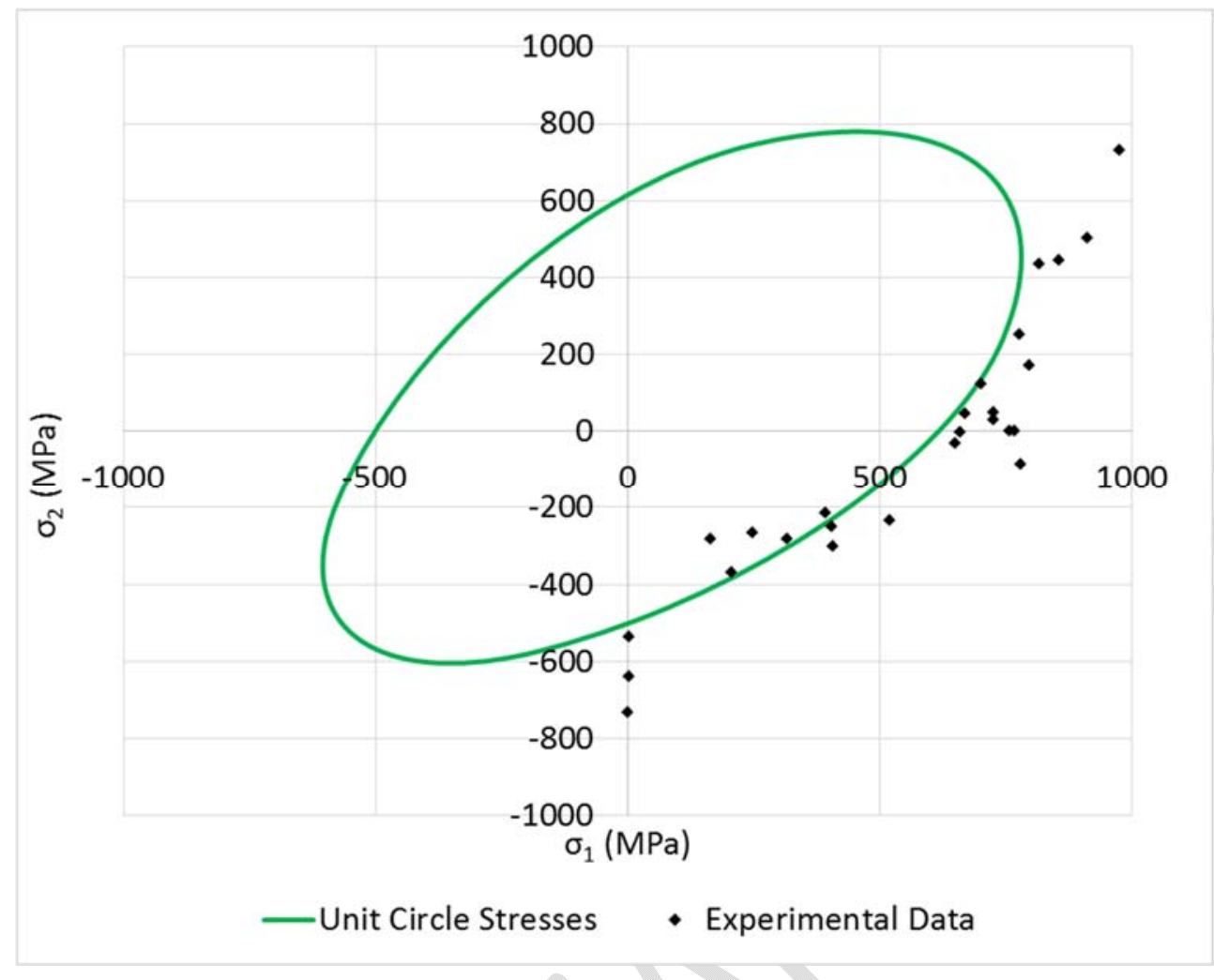

Figure 6 - Unit circle failure envelope for [0/士45/90]s AS4/3501-6 laminate, established in stress space, with experimental data from the WWFE [19], [20] 


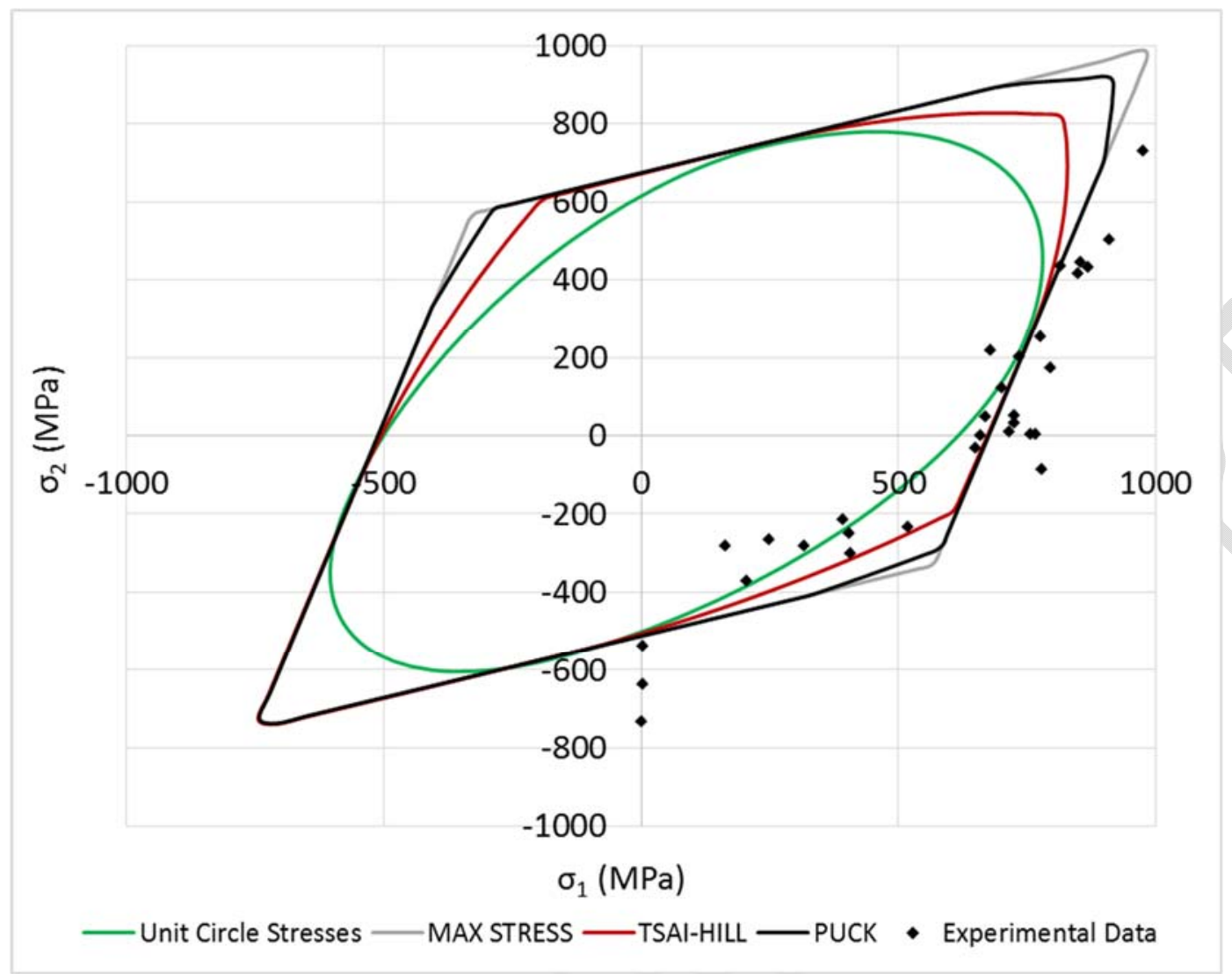

Figure 7 - Comparison of unit circle failure envelope, established in stress space, for [0/₫45/90]s AS4/3501-6 laminate with other failure criteria 


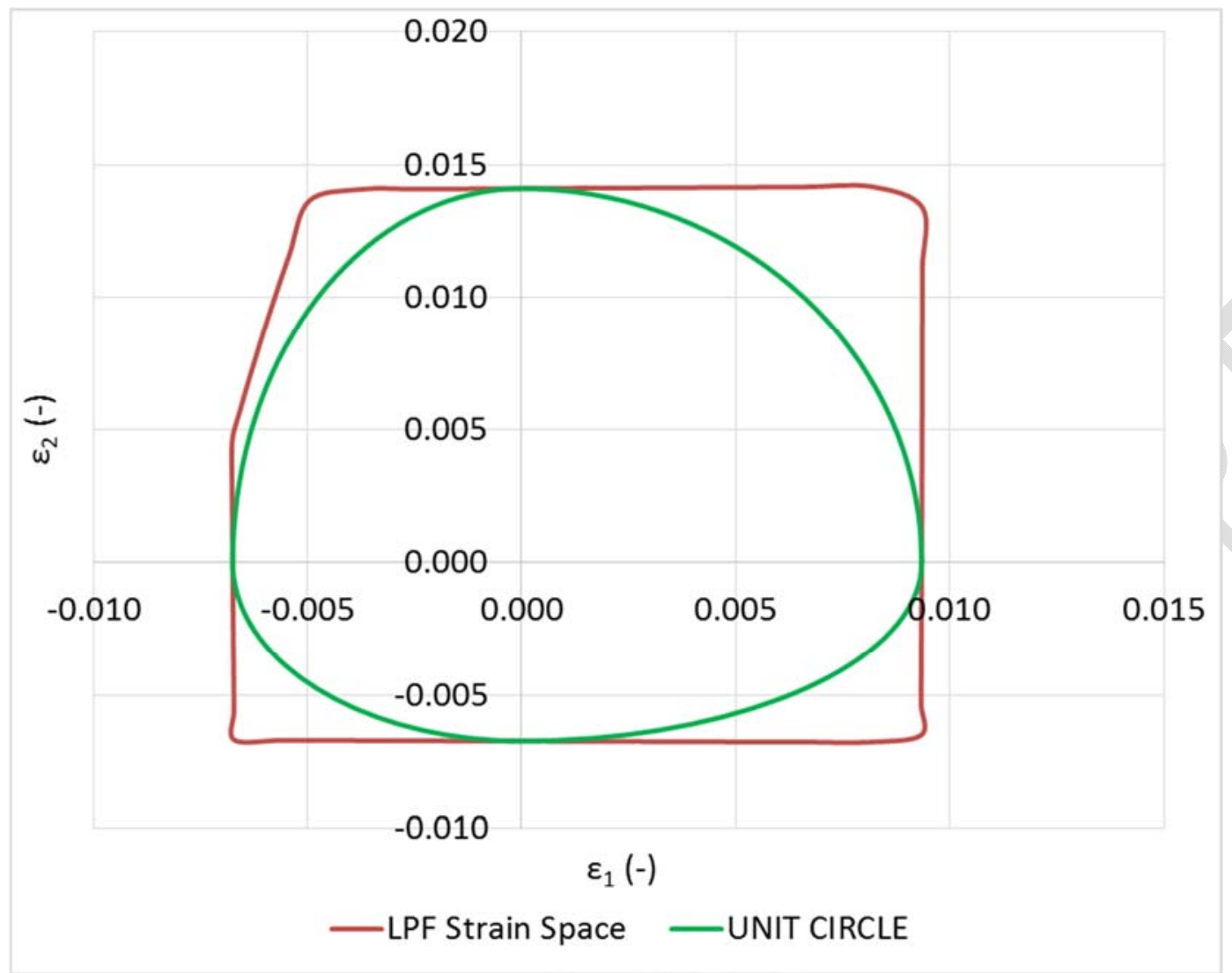

Figure 8 - Strain Space Unit Circle Failure Envelope for complex hybrid laminate (Propriety 5HS / UD / NCF combinations of $0^{\circ}, 45^{\circ}, 90^{\circ}, 135^{\circ} 8$ ply layup) 